REVISTA X, Curitiba, volume 12, n.3, p.102-114,2017.

\title{
AS POLÍTICAS LINGUÍSTICAS E O ENSINO DE ESPANHOL NO PARANÁ
}

\section{Language policies and the teaching of Spanish in Paraná}

\author{
Regiane de Fátima Siqueira ALBERTI - UEPG ${ }^{1}$ \\ Valeska Gracioso CARLOS - UEPG ${ }^{2}$
}

\begin{abstract}
RESUMO: Este trabalho pretende refletir sobre o panorama do ensino de espanhol no estado do Paraná. Tem como objetivo geral verificar como está se efetivando o ensino desta língua estrangeira, desde sua obrigatoriedade, a qual teve início com a LDB de 1996 e posteriormente com a Lei $\mathrm{n}^{\circ} 11.161 / 2005$, até os dias atuais. Nesse sentido, pauta-se nos estudos de CALVET (2007), RAJAGOPALAN (2014), CASTELLANO RODRIGUES (2011), CORREA (2014), LAGARES (2013), para apresentar um breve histórico do ensino da língua espanhola como Língua Estrangeira Moderna (LEM), como também dos conceitos que perpassam o termo políticas linguísticas. Juntamente aos aportes teóricos, acrescenta-se pesquisa documental, com dados estatísticos sobre as escolas que possuem o espanhol em sua matriz curricular de Ensino Fundamental e Médio, o número de CELEM e o número de professores de espanhol atuantes no ensino público no Paraná, bem como documentos oficiais pesquisados no portal da Secretaria de Educação do Paraná (SEED) ${ }^{3}$. As incursões nesses dados e documentos objetivam buscar entendimento sobre as políticas linguísticas elaboradas e efetivamente implementadas pelo poder público, e embasam a discussão teórico-prática que envolve o referido processo.
\end{abstract}

PALAVRAS-CHAVES: políticas linguísticas; ensino de espanhol como LEM; SEEDPR.

ABSTRACT: This work is reflected on the perspective of teaching Spanish in the state of Paraná. Its general objective is to verify how the teaching of this foreign language is taking place, since its mandatory, which began with the LDB - (Law of Guidelines and basis of Education) from 1996 and later with Law 11,161 / 2005, until the present day. In this sense, it is based on the studies of CALVET (2007), RAJAGOPALAN (2014), CASTELLANO RODRIGUES (2011), CORREA (2014), LAGARES (2013), to present a brief history of teaching Spanish as a Modern Foreign Language (LEM), but also of the concepts that permeate the term linguistic policies. In addition to the theoretical contributions, documentary research is added, with statistical data about the schools that

\footnotetext{
1 Mestranda no curso de Pós-Graduação em Linguagem Identidade e Subjetividade da UEPG Universidade Estadual de Ponta Grossa, 2016. Professora da rede pública estadual de ensino do Paraná, na área de Espanhol.

${ }^{2}$ Professora, e Doutora, atua no curso de Pós-Graduação em Linguagem Identidade e Subjetividade na Universidade Estadual de Ponta Grossa. (UEPG)

${ }^{3}$ Secretaria Estadual de Educação.
} 
have Spanish language in their curricular matrix of elementary and high school, the number of CELEM - (Center of Modern Foreign Languages) and the number of Spanish teachers working in public education in Paraná, as well as official documents researched on the website of the Secretary of Education of Paraná (SEED). The incursions in these data and documents seek to understand the linguistic policies elaborated and effectively implemented by the public power, and base the discussion on theoretical-practical that involves the referred process.

KEYWORDS: language policies; teaching Spanish as a modern foreign language; Secretariat of Education of Paraná - SEED-PR

\section{INTRODUÇÃO:}

A opção por refletir sobre políticas linguísticas e o ensino de espanhol, originouse do contexto escolar, onde surgem dúvidas referentes à efetivação de leis e ao papel do professor de línguas como conhecedor de todo processo que diz respeito a seu objeto de trabalho. Essas e outras indagações mostraram-se relevantes durante meus estudos no Mestrado, na disciplina de "Políticas Linguísticas" 4.

Pretendemos neste trabalho, fazer uma análise, de cunho teórico e documental, que possa revelar como está se efetivando o ensino de espanhol como língua estrangeira no Paraná, desde sua implementação até os dias atuais. As principais justificativas das problematizações apresentadas são as de valorizar a língua espanhola e seus educadores, bem como toda prática que envolve o ensino-aprendizagem desse idioma e trazer ao conhecimento de outros pesquisadores os números atuais do espanhol nas escolas públicas do estado do Paraná.

Primeiramente, buscamos definir o termo política linguística, para melhor esclarecer a relação desta com a implementação do ensino de espanhol no Brasil. Em seguida apresentamos um breve histórico da língua espanhola em nosso país, e destacamos as políticas linguísticas evidenciadas nas leis e pareceres no estado do Paraná.

Sobre a metodologia de pesquisa, procuramos justificar a escolha pela pesquisa teórico-documental, de cunho quantitativo, mostrando sua relevância para a análise dos dados estatísticos sobre as escolas que possuem o espanhol em sua matriz curricular, no Ensino Fundamental - séries finais, no Ensino Médio e que também possuem o

\footnotetext{
${ }^{4}$ Artigo realizado como forma de avaliação na disciplina de Políticas Linguísticas, do Mestrado de Linguagem, Identidade e Subjetividade, da UEPG (Universidade Estadual de Ponta Grossa), ministrada pela profa. Dra. Leticia Fraga.
} 
CELEM $^{5}$, são apresentados e discutidos à luz da revisão teórica e documental que embasam este trabalho.

Sendo assim, as considerações finais sinalizam que ainda há muito que se fazer para que as políticas linguísticas implementadas no estado do Paraná, possam ser evidenciadas em números mais significativos sobre o ensino de espanhol nas escolas públicas de nosso estado.

\title{
1. As políticas linguísticas e a língua espanhola:
}

Política linguística é um termo muito amplo e complexo, que enquanto campo de saber possui muitas particularidades, vem sendo nos últimos tempos objeto de estudo e pesquisa e, para que se possa entender seu significado, nos valemos de alguns conceitos que embasam este estudo. Rajagopalan esclarece:

\begin{abstract}
À política linguística concerne uma série de atividades relativas à política, ao planejamento, à planificação, à proteção, à manutenção, ao cultivo e, como não podia deixar de ser, de outra forma, ao ensino da (s) língua (s) que fazem parte do patrimônio linguístico de um país, de um estado, enfim, de um povo. Ela envolve a tomada de decisões e a implementação de ações concretas que têm consequências duradouras e, com frequência, balizam e determinam o rumo a ser tomado nos próximos anos ou décadas - ou até mesmo para períodos ainda maiores. (RAJAGOPALAN, 2014, p. 73)
\end{abstract}

Mesmo amplamente desconhecida por muitos educadores, as questões relacionadas à política linguística, estão cada vez mais evidentes, principalmente no que se refere ao ensino de línguas. Como vimos nas considerações acima, a política linguística engloba todo um processo de ensino-aprendizagem, manutenção, regulamentação e implementação do ensino de línguas num país. "Há um consenso crescente de que há muito mais política em matéria de ensino de línguas do que se pensava até recentemente" (RAJAGOPALAN, 2014, p.73). Ou seja, não há como negar o papel político que a linguística exerce quando atua nas práticas de ensino de línguas, quando entendida como uma atividade "na qual todo cidadão, tem o direito e o dever de participar em condições de absoluta igualdade" [...] (RAJAGOPALAN, 2013, p. 22).

De forma semelhante, em Calvet (2007) observamos o binômio política linguística e planejamento linguístico:

Política linguística, seria a determinação das grandes decisões referentes às relações entre as línguas e sociedade e o planejamento linguístico, seria sua

\footnotetext{
${ }^{5}$ Centro de Línguas Estrangeiras Modernas - SEED - PR.
} 
implementação, conceitos recentes que englobam apenas em parte essas práticas antigas. (CALVET, 2007, p. 11)

Ao analisarmos esse binômio do qual fala Calvet, podemos entender que "a Política linguística elabora um tipo de intervenção sobre diferentes situações e que o planejamento linguístico, são os meios para se fazer essa intervenção" (Calvet, 2007, p. 19) e que se pensarmos essa realidade no que se refere ao ensino de espanhol no Brasil, podemos entender muito do que foi proposto e do que realmente está sendo feito no que se refere concretização dessa realidade em nossa educação.

"O ensino de línguas estrangeiras é claramente uma questão política", como defende Rajagopalan (2006, Apud LAGARES, 2013, p.185), pois atitudes e ações metodológicas que acontecem em sala de aula são reflexos de decisões tomadas em outras instâncias, como Secretarias e Ministérios de Educação. LAGARES (2013, p. 185) nos esclarece que:

A própria decisão sobre as línguas estrangeiras que integram o currículo escolar é consequência de debates sociais e medidas legislativas que surgem em contextos geopolíticos e econômicos concretos. Na discussão que deu origem à Lei 11.161/2005, encontram-se justificativas referentes à aspectos geoestratégicos, relacionados com a integração da América Latina e com certo imaginário do Brasil como 'ilha linguística' entre seus vizinhos de língua espanhola. (LAGARES, 2013, p. 185)

Frente a essa justificativa podemos perceber a situação linguística e geopolítica em que se encontrava o Brasil frente aos vizinhos da América Latina e que as questões políticas foram determinantes para a decisão tomada pelo governo brasileiro em implementar o processo de obrigatoriedade da língua espanhola em nosso país, bem como a importância da língua na comunicação global.

A presença da língua espanhola na educação brasileira não se iniciou apenas com a obrigatoriedade da Lei 11.161 de 5/08/2005, como nos informa Daher, 2006 (Apud RODRIGUES, 2011, p. 15):

A primeira referência a esta língua na rede oficial de ensino, foi em 1919, no
Colégio Pedro II, no Rio de Janeiro, quando o professor Antenor Nascentes,
foi aprovado em concurso para ocupar a cátedra de língua espanhola daquela
instituição. Nesse momento, porém, a língua espanhola não fazia parte das
disciplinas de línguas estrangeiras obrigatórias que a legislação daquele
período previa para os currículos escolares (DAHER, 2006, Apud
RODRIGUES, 2011, p.15).

Outras leis surgiram tentando incluir o espanhol como disciplina obrigatória nos currículos de ensino, como a Lei Orgânica do Ensino Secundário, de 1942, que 
Rodrigues (2011, p. 16) explica como um "conjunto de medidas que pretendiam reestruturar a educação nacional, que determinava o ensino de espanhol durante o $1^{\circ}$ ano dos cursos Clássico ou Científico e possuía uma carga horária inferior às demais línguas estrangeiras ensinadas". Esse panorama foi alterado radicalmente em 1961 com a primeira Lei de Diretrizes e Bases da Educação (LDB), na qual não se encontra nenhuma referência ao ensino de línguas estrangeira, no entanto, essa lei criava os Conselhos Estaduais de Educação (CEEs), que teriam poder de incluir disciplinas obrigatórias e determinar quais seriam optativas, tendo como referências as particularidades de cada região. O espanhol, entre o francês e o inglês, foi o que teve menor poder de adesão no currículo desse período, o que colaborou para que o ensino de língua espanhola praticamente desaparecesse dos currículos das escolas brasileiras e voltasse a ser discutido apenas com a aprovação da Lei n ${ }^{\circ} 11.161$ de 2005.

A LDB de 1996 e a Lei $n^{\circ} 11.161$ foram responsáveis por alterar as determinações sobre o ensino de línguas estrangeiras aprovadas até então. $\mathrm{O}$ artigo $36^{\circ}$, inciso III da seção referente ao Ensino Médio dessa legislação afirma que "será incluída uma língua estrangeira moderna, como disciplina obrigatória, escolhida pela comunidade escolar, e uma segunda, em caráter optativo, dentro das possibilidades da instituição" (BRASIL, 1996).

No estado do Paraná ${ }^{6}$, a Deliberação 06/097 , aprovada em 15/12/2009, trata da oferta de ensino de língua espanhola obrigatória em todos os estabelecimentos de ensino públicos e privados do Sistema Estadual de Ensino do Estado do Paraná que ofertam o Ensino Médio, definindo em seu Artigo $1^{\circ}$, a data da implantação no início do ano letivo de 2010 , e no $\S 1^{\circ}$ para o ensino fundamental - anos finais, fica facultativa a inclusão da Língua Espanhola. O parágrafo único se refere aos estabelecimentos de ensino que

\footnotetext{
${ }^{6}$ PARANÁ. SEED. Secretaria de Estado da Educação. Departamento de Educação e Trabalho. Portal Dia-a-Dia Educação do Estado do Paraná. Educadores. Legislação de Língua Estrangeira. 2016. Disponível em: http://www.lem.seed.pr.gov.br/modules/conteudo/conteudo.php?conteudo=349 Acesso em 10-07-2016.

${ }^{7}$ Art. $1^{\circ}$ A oferta do ensino da Língua Espanhola, com matrícula facultativa ao aluno, passa a ser obrigatória em todos os estabelecimentos de ensino públicos e privados do Sistema Estadual de Ensino do Estado do Paraná, que ofertam o Ensino Médio. I - A oferta da Língua Espanhola deverá ser implantada no início do ano letivo de 2010. II - O aluno ou seu responsável deverá manifestar sua opção no momento da matrícula. III - Nos estabelecimentos de ensino que já ofertam a Língua Espanhola de forma obrigatória, a matrícula passa a ser obrigatória para o aluno, restando facultativa a matrícula em outra língua estrangeira moderna.

$\S 1^{\circ}$ É facultada a inclusão da Língua Espanhola nos currículos plenos dos anos finais do Ensino Fundamental.
} 
possibilitando ao aluno cursar a Língua Espanhola em Centro de Línguas Estrangeiras Modernas, terão cumprido o que determina a Lei Federal no 11.161/05.

Diferente disso, a Instrução ${ }^{8}$ 004/2010 - SUED $^{9} /$ SEED orienta a oferta da disciplina de Língua Espanhola, de maneira facultativa para o aluno, nos estabelecimentos da Rede Estadual de Ensino que ofertam Cursos de Ensino Médio, na modalidade da Educação de Jovens e Adultos; de Educação Profissional Integrada ao Ensino Médio; de Educação Profissional de Nível Médio Integrada à Educação de Jovens e Adultos - PROEJA e, de Formação de Docentes da Educação Infantil e dos Anos Iniciais do Ensino Fundamental, na modalidade Normal de Nível Médio.

Em consonância com a LDB de 1996, a Instrução Nº 021/2010 - SUED/SEED, estabelece que as escolas deverão elaborar nova Matriz Curricular para os anos finais do Ensino Fundamental e Ensino Médio com implantação simultânea para o ano de 2011 e na parte diversificada dessa Matriz, deverá estar especificada uma Língua Estrangeira, como disciplina obrigatória, definida pela comunidade escolar, observando-se a disponibilidade de professor habilitado e as características da comunidade atendida.

No Ensino Médio, a Parte Diversificada deverá ser composta, obrigatoriamente pela LEM - Espanhol e por uma segunda língua estrangeira moderna, escolhida pela comunidade escolar, sendo que uma será obrigatória e a outra optativa ao aluno, observando-se a disponibilidade de professor habilitado e as características da comunidade atendida. A disciplina escolhida pela comunidade escolar como optativa será ministrada através do programa do CELEM, sendo sua matrícula facultativa ao aluno, estando este sujeito às normas exaradas na Instrução nº 19/2008 SUED/SEED do CELEM.

Os critérios atuais para a implantação do CELEM estão previstos na Instrução No 010/2013 - SUED/SEED que determina as línguas ofertadas nesse curso, a carga

\footnotetext{
8 A Instrução Normativa pode ser definida como um ato puramente administrativo, uma norma complementar administrativa, tende a completar o que está em uma Portaria de um superior hierárquico, num Decreto Presidencial ou em uma Portaria Interministerial. Desta forma, jamais poderá inovar o ordenamento jurídico, nem passar colidir com Leis ou decretos, pois estes devem guardar consonância com as Leis. A instrução Normativa é expedida pelos superiores dirigentes dos órgãos, seja pelo representante maior do órgão em questão, ou pelo dirigente delegado para tais atribuições. Desta feita, a Instrução Normativa diz o que os agentes daquele órgão público devem seguir, executar, fazer ou respeitar, bem como descreve a respeito das atribuições que devem ser seguidas por aqueles parâmetros específicos naquele ato administrativo. Em síntese, a Instrução Normativa é um ato administrativo o qual deve estar em consonância com todo o ordenamento jurídico.
}

\footnotetext{
${ }^{9}$ Superintendência de Educação.
} 
horária, a oferta para alunos e para comunidade, o funcionamento, a avaliação, bem como os requisitos para os educadores que desejem atuar nos cursos do CELEM.

Atualmente, no que se refere ao ensino de espanhol como LEM, os educadores, alunos e profissionais envolvidos no processo de ensino e aprendizagem de língua espanhola, estão vivendo um momento de muita insegurança frente às novas propostas apresentadas pelo atual governo para o Novo Ensino Médio no Brasil, fundamentado pela BNCC - Base Nacional Comum Curricular. Este projeto tem o intuito de mudar a estrutura atual do Ensino Médio, propondo a flexibilização da grade curricular, a qual permitirá que o estudante escolha a área de conhecimento para aprofundar seus estudos. O currículo novo do Ensino Médio:

\begin{abstract}
Será norteado pela Base Nacional Comum Curricular (BNCC), obrigatória e comum a todas as escolas (da educação infantil ao ensino médio), [...] abrangendo as 4 áreas do conhecimento e todos os componentes curriculares do ensino médio definidos na LDB e nas diretrizes curriculares nacionais de educação básica. [...] A reforma torna o inglês obrigatório desde o $6^{\circ}$ ano do ensino fundamental e no ensino médio. Os sistemas de ensino poderão ofertar outras línguas estrangeiras se assim desejarem, preferencialmente o espanhol. A língua inglesa é a mais disseminada e a mais ensinada no mundo inteiro. (BRASIL, 2017, questões 2 e 10. Novo Ensino Médio- Dúvidas)
\end{abstract}

Sendo assim, o atual contexto político prevê a obrigatoriedade do ensino de língua inglesa no Ensino Médio e Fundamental, o que pode configurar um retrocesso frente a todas as conquistas em busca do plurilinguismo no Brasil.

No que diz respeito às políticas linguísticas adotadas, estas são as leis, pareceres e deliberações, que sustentam até os dias atuais o ensino de espanhol no Brasil e de maneira pontual, no estado do Paraná, relacionado assim ao que Calvet (2007, p. 11) nos explicou, seriam "a determinação das grandes decisões referentes às relações entre as línguas e sociedade".

\title{
2. Resultados e discussão sobre os dados estatísticos referentes ao ensino de espanhol no Paraná:
}

Para atender aos objetivos propostos neste trabalho, além de estudos teóricos, faz-se também uma análise documental referente aos dados sobre o espanhol nas escolas públicas do Paraná, uma vez que este trabalho se enquadra na abordagem quantitativa de pesquisa.

A variável explicada neste estudo, são os dados atuais do espanhol no Paraná e a variável independente (explicação), são as políticas linguísticas efetivamente 
cumpridas, bem como os atores sociais, para esclarecer melhor a escolha dos procedimentos metodológicos adotados apresento a reflexão de Silva (2009, p. 4556) sobre a pesquisa documental:

\begin{abstract}
A pesquisa documental, enquanto método de investigação da realidade social, não traz uma única concepção filosófica de pesquisa, pode ser utilizada tanto nas abordagens de natureza positivista como também naquelas de caráter compreensivo, com enfoque mais crítico. Essa característica toma corpo de acordo com o referencial teórico que nutre o pensamento do pesquisador, pois não só os documentos escolhidos, mas a análise deles deve responder às questões da pesquisa, exigindo do pesquisador uma capacidade reflexiva e criativa não só na forma como compreende o problema, mas nas relações que consegue estabelecer entre este e seu contexto, no modo como elabora suas conclusões e como as comunica. Todo este percurso está marcado pela concepção epistemológica a qual se filia o investigador (SILVA, et al., 2009, p.4556).
\end{abstract}

Sobre a coleta de documentos, vale ressaltar que a pesquisa e a seleção de materiais a serem utilizados são de suma importância para o pesquisador e seu objeto de estudo e irá influenciar diretamente no sucesso da análise:

Deste modo, a tarefa de pré-análise passa a orientar novas coletas de dados, considerando que o processo é realizado de forma mais prudente e cautelosa com a intenção de alcançar melhores resultados na análise crítica do material recolhido (SILVA, et al., 2009, p.4558).

No caso dos dados em questão, acredita-se que a escolha foi adequada, justamente por permitir que a análise acontecesse de maneira a dialogar com os pressupostos teóricos selecionados para este estudo, ou seja, problematizar a realidade atual do ensino do espanhol em nosso estado. Os dados atuais foram pesquisados no site da SEED em números e alguns foram fornecidos via e-mail por funcionários da SEED (Secretaria de Educação do Paraná). Os documentos foram retirados do portal do MEC e do portal dia-a-dia educação.

Em consonância ao tempo estipulado pela Lei de $\mathrm{n}^{\mathrm{o}}$. 11.161/2005 (BRASIL, 2005), que torna obrigatório o espanhol no currículo, os estados precisaram se organizar e implantar o espanhol como componente curricular em suas escolas. Para tanto, a Secretaria de Estado de Educação do Paraná, na época, realizou dois concursos públicos em 2004 e 2007 os quais um dos motivos estava relacionado ao aumento da demanda na rede estadual devido à implementação de mais uma LEM (Língua Estrangeira Moderna) obrigatória no currículo escolar do ensino médio, neste caso, o espanhol, e, consequentemente, a expansão de ofertas dos cursos do CELEM em todo estado. 
REVISTA X, Curitiba, volume 12, n.3, p.102-114,2017.

Passados onze anos da obrigatoriedade do ensino do espanhol, o panorama nas escolas públicas do estado do Paraná, se apresenta da seguinte forma:

\begin{tabular}{|c|c|c|c|c|c|}
\hline \multicolumn{6}{|c|}{ DADOS ESPANHOL-ESCOLAS/ MODALIDADE DE ENSINO $^{10}$} \\
\hline \multirow{5}{*}{$\begin{array}{c}\text { Ensino } \\
\text { Fundamental } \\
6^{\circ} \text { a } 9^{\circ} \text { anos }\end{array}$} & Ensino & Ensino & Ensino & CELEM & CELEM \\
\hline & Fundamental & Médio & Médio & BÁSICO & APRIMORAMEN \\
\hline & $6^{\circ}$ a $9^{\circ}$ anos & & com & & TO \\
\hline & com Espanhol & & Espanhol & & \\
\hline & na Matriz & & na Matriz & & \\
\hline 1882 & 47 & 1517 & 212 & 969 & 117 \\
\hline
\end{tabular}

Tabela 1: Dados espanhol - Escolas/Modalidades de Ensino. Dados organizados pelo autor.

Pensando nas políticas linguísticas que foram propostas para o ensino de espanhol no Paraná, a instrução No 021/2010 - SUED/SEED determinou que os estabelecimentos de ensino elaborassem uma nova matriz curricular para o ano de 2011, e que a língua estrangeira deveria estar especificada como disciplina obrigatória, escolhida pela comunidade escolar, observando a disponibilidade de professores habilitados e as características da comunidade atendida. No entanto, o que se percebe é que apenas 2,5\% das escolas públicas possuem o espanhol como língua estrangeira moderna, na matriz curricular do Ensino Fundamental - séries finais. Em muitos casos, foi realizada a escolha da língua estrangeira, em outros, optou-se por deixar da maneira como estava a matriz antiga. Muitos podem ter sido os motivos para que tal fenômeno acontecesse, porém, este estudo não buscou abranger tal conhecimento.

Com relação ao Ensino Médio, o que podemos apontar é que 14\% das escolas possuem o espanhol em sua matriz curricular. Esse percentual é maior em relação às séries finais do Ensino Fundamental, e evidencia o caráter obrigatório, que a lei lhe confere. No entanto, esses números ainda estão muito aquém do que se espera.

\footnotetext{
${ }^{10}$ Estes dados correspondem ao levantamento de Instituições de Ensino e Matrículas para o ano de 2016, informados pelos NREs, bem como dados retirados do site da SEED em números: escolas/turmas, in: http://www4.pr.gov.br/escolas/numeros/, acesso em 10/07/2016.
} 
Sobre as turmas de CELEM no Paraná, percebemos que os números são bem expressivos no $1^{\circ}$ ano/Básico e que no Aprimoramento/ $2^{\circ}$ ano, há uma queda de quase $88 \%$ em relação aos que iniciaram o curso. Sobre isto, a SEED informa que muitas escolas ofertam a língua espanhola no CELEM, em cumprimento à lei, porém solicitam o fechamento de turmas devido a não opção de curso realizada pelos alunos e ao fato de não possuírem o número suficiente de alunos para o prosseguimento do curso. Dadas as diferenças evidentes nos números apresentados, entende-se que o CELEM se apresenta como a maior evidência da efetivação do ensino do espanhol no Paraná, ainda que neste ano, até o momento, houve o fechamento de muitas turmas de CELEM, diminuindo os índices acima citados. ${ }^{11}$

Quanto ao número de professores de espanhol que compõem o quadro educacional nas escolas públicas paranaenses, temos os seguintes dados:

\begin{tabular}{|c|c|}
\hline \multicolumn{2}{|c|}{ PROFESSORES DE ESPANHOL NO PARANÁ $^{\mathbf{1 2}}$} \\
\hline VÍNCULO & NÚMERO $^{|c|}$ \\
\hline QPM-P: Quadro Próprio do Magistério & 575 \\
\hline $\begin{array}{c}\text { QPM- E: Especialistas do Quadro } \\
\text { Próprio do Magistério }\end{array}$ & 6 \\
\hline $\begin{array}{c}\text { REPR.: Regime Especial - Prof. } \\
\text { TOTAL: }\end{array}$ & 541 \\
\hline
\end{tabular}

Tabela 2: Professores de espanhol no Paraná. Dados organizados pelo autor

Podemos observar que apesar da expansão da língua em nosso estado, da oferta de concursos, o número de professores QPM (Quadro Próprio do Magistério), ou seja, concursados, atinge pouco mais da metade do número total de professores em exercício. Nota-se que temos muitos professores de espanhol com contratos temporários (REPR.), conhecidos como PSS.

\section{Considerações finais:}

\footnotetext{
${ }^{11}$ SEED em números: http://www4.pr.gov.br/escolas/numeros/frame_geralturmat.jsp?ano=2017

12 Dados retirados do site da SEED em números: professores/especialistas. In: http://www4.pr.gov.br/escolas/numeros/frame_geralprofpesarea.jsp?mes=07\&ano=2016, acesso em 12/07/2016.
} 
As políticas linguísticas adotadas no Brasil e também no estado do Paraná, no que se refere ao ensino de espanhol, acabam por terceirizar a língua estrangeira, como afirma Lagares (2013, p.185), "entendida como matéria extracurricular, com uma função exclusivamente veicular ou instrumental, expressada no senso comum de que escola não é lugar para aprender língua estrangeira".

Sobre isto, podemos compreender os números apresentados neste estudo, no que diz respeito às modalidades de ensino. Ao mesmo tempo em que a SEED na Deliberação 06/09 de 2009, preconiza que as escolas públicas e privadas, que ofertam Ensino Médio, deveriam contemplar o espanhol em suas matrizes curriculares, em seu parágrafo único, estabelece que todos os "estabelecimentos de ensino que possibilitando ao aluno cursar a Língua Espanhola em Centro de Línguas Estrangeiras Modernas (CELEM), teriam cumprido o que determina a Lei Federal no 11.161/05”, dessa forma, a maioria das escolas optou e continua optando por implantar o CELEM, como uma medida mais "fácil" e "apaziguadora" de se fazer cumprir a obrigatoriedade da língua espanhola, sem haver contrariedades com outros professores de outras línguas estrangeiras, de modo particular, o inglês, já que desde os tempos da LDB (1961), ocupa predominantemente o lugar de língua estrangeira moderna, como nos informa Lagares (2013, p. 186):

Por questões sobretudo comerciais e socioeconômicas, relacionadas com sua hegemonia como língua do capitalismo mundial, o inglês, passa a ser identificado com a 'língua estrangeira moderna' por excelência, sem que haja qualquer dispositivo legal para mudar essa realidade” (LAGARES, 2013, p.186).

Isso se torna evidente no momento atual, onde toda comunidade escolar envolvida no processo de ensino e aprendizagem de língua espanhola, vive um momento de muita insegurança e expectativas, frente às novas propostas apresentadas pelo atual governo para o Novo Ensino Médio no Brasil.

Respondendo à pergunta de pesquisa, entende-se que a inclusão do espanhol no currículo escolar do Paraná e as políticas linguísticas implementadas até a Lei se efetivaram a luz das leis federais, cumprindo o que se determinou, ainda que essa oferta seja insuficiente, principalmente no que se refere à matriz curricular do Ensino Fundamental e Médio, ou seja, políticas linguísticas e planejamento linguístico, não se efetivaram em consonância. Vale ressaltar que para os próximos anos, o Paraná deve se estruturar e seguir o governo federal quanto a Lei do Novo Ensino Médio. 
Entende-se que essa discussão abre vários questionamentos sobre os fenômenos que concorrem para que o ensino de espanhol ainda não esteja alcançando números satisfatórios em nosso estado. Faz-se necessárias muitas pesquisas nas áreas educacionais e político-pedagógicas no que tange o ensino-aprendizagem da língua em questão. Estudos sobre formação de professores, materiais didáticos, readequação de currículo, gestão pública e escolar, importância de políticas linguísticas no mundo capitalista neoliberal, entre outros fatores que contribuam para uma política educacional de qualidade, que respeite a pluralidade linguística e sociocultural na qual o sujeito está inserido.

\section{REFERÊNCIAS BIBLIOGRÁFICAS:}

BRASIL, Ministério da Educação. Lei no. 11.161/05, de 05 de agosto de 2005. Dispõe sobre o ensino da Língua Espanhola. Disponível em: http://www.planalto.gov.br/ccivil_03/_Ato2004-2006/2005/Lei/L11161.htm>, acesso: 21-jun-2016

Lei $N^{o}$ 9.394, de 20 de dezembro de 1996. Disponível em: http://www.planalto.gov.br/ccivil_03/leis/L9394.htm. Acesso: 21/06/2016

CASTELLANO RODRIGUES, F.S.; Leis e línguas: o lugar do espanhol na escola brasileira. Disponível em:

http://portal.mec.gov.br/index.php?option=com_docman\&view=download\&alias=78362011-espanhol-capa-pdf\&category_slug=abril-2011-pdf\&Itemid=30192. Acesso em: $30 / 06 / 2016$

CORRÊA, D. A. (Org.) Política linguística e ensino de língua. 01. Ed. Campinas: Pontes, 2014. V. 01. 112p.

LAGARES, X. C. Ensino de espanhol no Brasil: uma (complexa) questão de política linguística. In: NICHOLAIDES, C. Et.al (Orgs); Política e Políticas Linguísticas. Campinas, SP: Pontes Editores, 2013.

OLIVEIRA, Lenice Iolanda de. A Lei e a Instrução Normativa: A força da Instrução Normativa. Disponível em: http://www.rochamarques.com.br/site/wpcontent/uploads/pdf/a-lei-e-a-instrucao-normativa.pdf. Acesso em 21/09/2016.

PARANÁ. SEED. Secretaria de Estado da Educação. Departamento de Educação e Trabalho. Portal Dia-a-Dia Educação do Estado do Paraná. 2016. Disponível em http://www.lem.seed.pr.gov.br/modules/conteudo/conteudo.php?conteudo=349 Acesso em 10-07-2016

Instrução- CELEM. 19/2008. Disponível em:

http://www.lem.seed.pr.gov.br/arquivos/File/celem/instrucao192008.PDF. Acesso em: 10/07/2016 
REVISTA X, Curitiba, volume 12, n.3, p.102-114,2017.

Deliberação - CELEM. 0609. Disponível em:

http://www.lem.seed.pr.gov.br/arquivos/File/celem/deliberacao0609.pdf. Acesso em: $10 / 07 / 2016$

Instrução - CELEM. 04/2010. Disponível em:

http://www.lem.seed.pr.gov.br/arquivos/File/celem/instrucao42010.pdf. Acesso em: $10 / 07 / 2016$

Instrução - CELEM. 21/2010. Disponível em:

http://www.lem.seed.pr.gov.br/arquivos/File/celem/instrucao212010.pdf. Acesso em: $10 / 07 / 2016$

Instrução - CELEM. 10/2013. Disponível em:

http://www.lem.seed.pr.gov.br/arquivos/File/celem/instrucao10_2013.pdf. Acesso em: $10 / 07 / 2016$

RAJAGOPALAN, K. O professor de línguas e a suma importância do seu entrosamento na política linguística do seu país. In: CORREA: D. A. (org.) Política Linguística e Ensino da Língua. Campinas, SP: Pontes Editores, 2014. p. 73-82

Política Linguística: do que é que se trata, afinal? In: Nicolaides, C.et. alii. (Org.). Políticas e Políticas Linguísticas. Campinas: Pontes/ALAB. 2013.

SILVA, L.R.C.Da; et.alii. (Org.). Pesquisa documental: Alternativa Investigativa na Formação Docente. IX Congresso Nacional de Educação - EDUCERE. III Encontro Sul Brasileiro de Psicopedagogia. 26-29/10/2009. PUC-PR. Disponínel em:

http://www.pucpr.br/eventos/educere/educere2009/anais/pdf/3124_1712.pdf. Acesso: $20 / 06 / 2$ 